\title{
Algal Multipurpose Benefit
}

\author{
Iyasu Gudisa \\ Field of Fishery, Limnology and Aquatic Ecotoxicology \\ College of Natural and Computational Science, Department of Biology, Madda Walabu University, Ethiopia \\ Po.box. 247 madda walabu University, Ethiopia
}

\begin{abstract}
Summary
Algae are the mass groups of photosynthetic agent that are able to contribute the variety food component and oxygen for the planet. The review emphasized on the benefits of algae for multipurpose. As a result, several research paper finding reviewed to be informed about algal benefit for different purposes. Many paper findings agreeing the algal potential to regulate the environment by reducing the concentration of corbondioxide, releasing the oxygen for organism's respiration and aeration to decompose the pollutant into usable nutrients. . And also several findings ascertain us the algae importance to increase the crop production by fixing the nitrogen biomass in agricultural fields and contribute to enhance high crop biomass production by change the nitrogen gas to utilizable form. They have also the potential to indicate the environmental pollution and have the potential to treat the wastes for reducing the pollutants concentration. Algae also contain all essential amino acids, Iodine, vitamins B1, B2, B6, niacin, carotene and minerals, while the presence of heavy metals is negligible. They are also used as extracts in food, cosmetics, and industrial uses. Moreover, they have been reported for their potential medicinal uses as antioxidant, anticancer, antiviral properties. Algal potential to produce biofuels production also has been many scholars' research findings. Generally algae are much important for ecology, economy, nutrition, health and production of fuels.
\end{abstract}

Keywords: Algae, biofuel production, Medicine, nitrogen fixation, bioindicator

DOI: $10.7176 /$ JNSR/9-23-01

Publication date: December $31^{\text {st }} 2019$

\section{Introduction}

Algae are the organisms found in both marine and freshwaters habitats. They are diverse group of single-cell photosynthetic organisms that include cyanobacteria and a wide range of eukaryotic algae and they offer the potential for rapid growth under photoautotrophic conditions, and they can grow in a wide range of habitats. (Gangl et al., 2015). They are the mass groups of photosynthetic agent that are able to contribute the variety food component and oxygen for the planet (Nivedita and Poonam, 2017). As a result, they are also regulating the world climate by reducing the concentration of corbondioxide for synthesizing sugar and release the most vital important oxygen gas as by product (Acevedo et. al.2017).

Algae as bio indicators give early warning for pollution in an ecosystem to awake the concern body to sustain the natural resources and whole ecosystem (Dulcie et.al, 2003). Some groups of algae are crucial to increase the crop production by fixing the nitrogen biomass in agricultural fields. Due to the important characteristic of nitrogen fixation, the algae have a unique potential to contribute to enhance high crop biomass production (Alam et al, 2014). Algae are the sources of bioactive metabolites and considered for the pharmaceutical industry in drug development. A number of algae contain high-value compounds such as oils, colorants, and polysaccharides, which are used by the food additive, oil, and cosmetic industries, among others (Gangl et al., 2015). Algae have many convincing properties to make it stand out in front of synthetic drugs (Aditya et. al, 2016). Algae play a vital role in the life of human beings as food, fodder, medicine (Sakthinathan, 2018; Tang and Suter, 2011) and biofuels production (Wigmosta et al., 2011; Nivedita and Poonam, 2017).

\section{Algal ecological benefits}

Algae have different pathways to fix atmospheric carbon dioxide and to efficiently utilize the nutrients to convert it into biomass. These photosynthetic organisms fix the atmospheric nitrogen into utilizable form and make it available to the plants (Nivedita and Poonam, 2017). They also form symbiotic associations and provide nourishment to the host. There is growth enhance due to hormones like cytokinin, gibberellins and auxin which accelerated growth. The molecules from these organisms like peptides, vitamins, carbohydrates are reported to induce pathogenesis in plants. The exo-polysaccharide of cyanobacteria improves the soil quality and fertility (Monika et. al., 2015).

Algae are as Biological indicators (bioindicators) offer a signal of the biological condition in an ecosystem (Alkhalifa et al., 2012). Because of their short generation times, microalgae respond rapidly to environmental changes, and any effect on them will affect to higher trophic levels. In addition, microalgae offer the possibility to study the trans-generational effects of pollutant exposure, being a model of choice for the study of the long term effects of pollutant exposure at population level. Furthermore, micro algal tests are generally sensitive, rapid and 
low-cost effective. For all these reasons, the use of microalgal toxicity tests is increasing, and today these tests are frequently required by authorities for notifications of chemicals and are also increasingly being used to manage chemical discharges (Cid et. al., 2012). Using these bioindicators as an early warning of pollution or degradation in an ecosystem it is possible to help sustain the natural resources and whole ecosystem (Dulcie et.al, 2003).

They are used to detect changes in the natural environment, monitor for the presence of pollution and its effect on the ecosystem in which the organism lives, monitor the progress of environmental cleanup and test substances, like drinking water, for the presence of contaminants. Alage are also used to treat the waste water. Algae are able to effectively remove a variety of pollutants and nutrients (Sukačová, Kand Červený, J., 2017; Acevedo et. al.2017)). The oxygen they produce by photosynthesis process is used as aeration to help aerobic bacteria to decompose the contaminants and convert into nutrients (Acevedo et. al.2017; Ramaraj et. al., 2010). This is cost effective eco-friend treatment and reduces the volatile contaminants from the environment (Acevedo et. al.2017)

\section{Algal Nutritional Benefits}

Algae produce a great variety of biological active compounds which cannot be found in other organisms. All essential amino acids presence in algae. Iodine, the most important component of sea vegetables is present in high amounts (Barre et.al, 2010) as well as the vitamins B1, B2, B6, niacin, carotene and minerals were found high, while the presence of heavy metals was negligible (Kolb et al., 2004). Therefore, they have high potential as a source of functional ingredients. It will be also referred that seaweeds can be a source of new compounds for drug discovery (Figueiredo et. al., 2016).

The incorporation of algae biomass in food is a way to design attractive and healthy new products. Algae have been credited with improving the immune system, the increasing of weight, the number of eggs, reproductive performance, or reducing cholesterol levels. And also algae used as animal in order to improve the quality of meat and eggs. Also, their importance in aquaculture is not surprising since they are natural food for these organisms (Dajana J. Kovač et al., 2013).

They are sources of nutrients like carotenoids and vitamin B12. Their health benefits as a complementary dietary source for macro and micro nutrients have been identified in various populations (Tang and Suter, 2011). High protein content of various algal species are alternative source of proteins, oils rich in some PUFAs seem particularly suitable for children, pregnant women, vegetarians and for different patients. Since algae also represent an important source of vitamins, minerals, antioxidants and natural colorants, the incorporation of the whole biomass in food and feed could be used to provide the color, increment nutritional value, and improve texture or resistance to oxidation (El-Baz, 2017).

\section{Algal medicinal benefits}

Certain beverages are prepared from sea algae. They are also used as extracts in food, dairy, cosmetics, and industrial uses. Mainly marine algae have been also used as medicine for many centuries. Moreover, they have been reported for their potential medicinal uses (Figueiredo et. al., 2016). Algae is used as one of important medical source due to its antioxidant, anticancer, antiviral properties. Therapeutic properties of algae is used for promotion of health .edible algae is recognized as complete foods which provides correct balance of proteins, carbohydrates ,vitamins , and minerals (Pooja, 2014). Algae are also used for several vaccine antigens, antibodies, sources of enzymes (Gangl et al, 2015).

There has been an increasing demand for dietary interventions for the prevention of chronic inflammatory diseases, such as cardiovascular disease (CVD) and nonalcoholic fatty liver disease (NAFLD) (Siah et.al., 2013). Antioxidative, antihypertensive, immunomodulatory, anticancerogenic, hepato-protective, and anticoagulant activities have been attributed to some microalgae-derived compounds such as peptides (Caporgno et.al, 2018). Algae can be an effective natural product for improving blood lipid profiles and for preventing inflammation and oxidative stress.

They contain bioactive components, namely, carotenoids, c-linolenic acid, fibers, and plant sterols, which can be beneficial for preventing CVD and NAFLD (Siah et.al. 2013). They inhibit intestinal cholesterol absorption and decrease hepatic lipids, lowering plasma total cholesterol, and triglyceride concentrations and decrease oxidative stress due to their free radical scavenging activity and inhibition of lipid peroxidation. According to ElBaz (2017), consuming alga filamentous is also good for intestinal tract of human, because it serve as roughage in the human diets, preventing constipation. Moreover, alga can be used as ingredient of food items such as cake, cookies, snack and noodle. Some species of algae are considered to be an important source for diet and food additives because it has high content of protein and minerals (Dine Naw and Soe, 2011). Algae are rich-sources of metabolites, which can be used to fight against oxidative stress and hence skin aging (Jean et. al., 2017).

\section{Algal Benefits for fuel production}

Algae biomass could serve as a resource for the production of renewable transport fuels, such as biodiesel and bio- 
ethanol (Voort et. al., 2015). Biodiesel has emerged as a promising substitute to petrodiesel because it is biodegradable, less toxic, and reduces greenhouse gas emission (Gumba et. el., 2016). Algae can produce large amount of cellular storage lipids in the form of triacylglycerols which can be readily converted to biodiesel via a simple chemical transesterification reaction with zero emissions of both air pollutants and greenhouse gases (Bisth et. al., 2015).

Algae have the potential to generate $220 \times 109 \mathrm{~L} \mathrm{yr}-1$ of oil, equivalent to $48 \%$ of current U.S. petroleum imports for transportation (Wigmosta et al., 2011). In fuel industry algae biofuels have been emerged as a clean, nature friendly, cost effective solution to other fuels (Gumba et. el., 2016). They have significant potential as a renewable biofuels feedstock, but the success of global algal biofuels initiatives will depend upon our ability to produce algal crops in a reliable, cost-effective and sustainable manner (Nivedita and Poonam, 2017).

\section{Conclusion}

Generally, algae are very crucial photosynthetic organisms used for production of high nutritive food, different drugs or therapeutics ingredients and renewable biofuel which has no environmental negative effects. Algae have the potential to indicate the environmental pollution and regulate the environment by consuming and decreasing carbon dioxide and releasing oxygen for pollutants decomposition so algae have the potential to treat wastes. Algae are also the sources of renewable fuel which has no environmental negative effects during their etraction

\section{References}

Ahmed A.H. Siddiga,b,, Aaron M. Ellison b, Alison Ochsc, Claudia Villar-Leemand, Matthew K. Laub. 2015. How do ecologists select and use indicator species to monitor ecological Change? Insights from 14 years of publication in Ecological Indicators. Ecological Indicators. $\mathrm{j}$ o ur na 1 ho me page www.elsevier. Com/locate/ecolind. 60:223-230

Alkhalifa A. H. , Ali A. Al-Homaidan, Afaf I. Shehata, Hussein H. Al-Khamis, Abdullah A. Al-Ghanayem and Abdelnasser S. S. Ibrahim. 2012. Brown macroalgae as bio-indicators for heavy metals pollution of Al-Jubail coastal area of Saudi Arabia. African Journal of Biotechnology Vol. 11(92). Pp: 15888-15895, 15. DOI: 10.5897/AJB12.2509 ISSN 1684-5315 C2012 Academic Journals

Aditya T., Bitu G and Mercy Eleanor G. 2016. The Role of Algae in Pharmaceutical Development. Journal of Pharmaceutics and Nanotechnology. Vol. 4.

Barre L.S., Philippe Potin, Catherine Leblanc and Ludovic Delage .2010. The Halogenated Metabolism of Brown Algae (Phaeophyta), Its Biological Importance and Its Environmental Significance. Mar. Drugs. 8 988-1010; doi: $10.3390 / \mathrm{md} 8040988$

Bisth T. S., Mayank A. P., Pandey and Veena Pande. 2015. Algal biofuel and their impact on Agriculture and Environment. Int.J.Curr.Microbiol.App.Sci 4(10): 586-604

Caporgno MP and Mathys A .2018. Trends in Microalgae Incorporation Into Innovative Food Products with Potential Health Benefits. Front. Nutr. 5:58. doi: 10.3389/fnut..00058

Clark, C. and Lands, B. 2015. Creating Benefits from Omega-3 Functional Foods and Nutraceuticals. Food and Nutrition Sciences. 6, 1613-1623. 4236/fns .617166

Cid, A., Prado, R., Rioboo, C., Suarez-Bregua, P, and Herrero, C. 2012. Use of Microalgae as Biological Indicators of Pollution: Looking for New Relevant Cytotoxicity Endpoints. In: Johnsen, M. N. (ed.) Microalgae: Biotechnology, Microbiology and Energy. Nova Science Publishers, New York. pp: 311-323.

Dajana J. Kovač1, Jelica B. Simeunović1, Olivera B. Babić1, Aleksandra Č. Mišan, Ivan Lj.Milovanović. 2013. Algae in food and feed, Food and Feed Research 40 (1), 21-31

Dulcie M. Linton, George F. Warner. Biological indicators in the Caribbean coastal zone and their role in integrated coastal management. Ocean \& Coastal Management 46. p. 261-276

Farouk K., El-Baz, Sayeda M. Abdo, Ahmed M.S. , Hussein. 2017. Microalgae Dunaliella salina for use as Food Supplement to Improve Pasta Quality. Int. J. Pharm. Sci. Rev. Res.,46(2). P: 45-51

Figueiredo, F., Encarnacao, T. and Campos, M.G. 2016. Algae as Functional Foods for the Elderly. 7, 1122-1148. http://dx.doi.org/10.4236/fns.2016.712107

Gangl Doris, Julie A. Z. Zedler, Priscilla D. Rajakumar, Erick M. Ramos Martinez, Anthony Riseley, Artur Włodarczyk, Saul Purton, Yumiko Sakuragi, Christopher J. Howe, Poul Erik Jensen, and Colin Robinson. 2015. Biotechnological exploitation ofMicroalgae. Oxford Univrsity press. Journal of Experimental Botany, Vol. 66, No. 22 pp 6975-6990

Gumba R.E., Saallah S., Misson M., Ongkudon C.M., Anton A. 2016. Green biodiesel Production: a review on feedstock, catalyst, monolithic reactor and supercritical fluid Technology. Biofuel Research Journal .11 pp. 431-447. DOI: 10.18331/BRJ2016.3.3.3

Jean-Yves Berthon, Rachida Nachat-Kappes, Mathieu Bey, Jean-Paul Cadoret, Isabelle Renimel \& Edith Filaire .2017. Marine algae as attractive source to skin care, free Radical Research, 51:6, 555-567, DOI: $10.1080 / 10715762.2017 .1355550$ 
Kolb N., Vallorani L., MilanovN. and Stocchi V. 2004. Wakame and Kombu as Food Supplements. Food Technol. Biotechnol. 42 (1) 57-61

Martín P. Caporgno and Alexander Mathys. 2018. Trends in Microalgae Incorporation Into Innovative Food Products with Potential Health Benefits. Volume $5 \mid$ Article 58

Moat War Dine Naw1 and Soe Soe Win. 2011. Morphology and Nutritional Values of Green Alga Cladophora from Kachin State. Universities Research Journal. 4(1)

Monika M. Jangir, Jyoti S. Kashyap, Vani B. and Shibashish Chowdhury. 2015. The Role of Cyanobacteria in Agriculture. Journal of Agroecology and Natural Resource. Volume 5: pp. 345-350

Pooja. 2014. Algae used as Medicine and Food-A Short Review. J. Pharm. Sci. \& Res. Vol. 6(1) 33 - 35

Ramaraj R., David D-W. Tsai, and Paris Honglay Chen. 2010. Journal of Soil and Water Conservation. 42 (4): 439-450 6(1) 33 - 35

Sakthinathan B. 2018. Economic Benefits of Aquatic Plants - A Review. Mod App Ocean \& etr Sci 1(3). MAOPS.MS.ID.000115. DOI: 10.32474/MAOPS. 01.000115

Shah Alam, Rajendra Kumar Seth and Shukla D.N. 2014. European Journal of Experimental Biology. 4(5):24-28

Sharma N. Sharma P. 2017. Industrial and Biotechnological Applications of Algae. Journal of advances in plant biology. Vol 1 (1).

Stephanie Acevedo, Nancy J. Pino§, Gustavo A. Peñuela. 2017. Ingeniería y Competitividad, Volumen 19, P. 185 $-193$

Siah C. K., Yue Yang, Youngki Park, and Jiyoung Lee. 2013. Health Benefits of Blue-Green Algae. Prevention of Cardiovascular Disease and Nonalcoholic Fatty Liver Disease. J Med Food 16 (2): 103-111

Sukačová, K., Červený, J. 2017. Can algal biotechnology bring effective solution for Closing the Phosphorus cycle? Use of algae for nutrient removal. European Journalof Environmental Sciences. Vol. 7, pp. 63-72 https://doi.org/10. 14712/23361964.

Tang, G. and Suter, P M .2011. Vitamin A, nutrition, and health values of algae: Spirulina, Chlorella, and Dunaliella. Journal of Pharmacy and Nutrition Sciences, 1(2):111-118. DOI: https://doi.org/10.6000/19275951.2011.01.02.04

Wigmosta, M. S., A. M. Coleman, R. J. Skaggs, M. H. Huesemann, and L. J. Lane.2011. National microalgae biofuel production potential and resource demand, Water Resour. Res., 47, W00H04, doi: 10.1029/2010WR009966.

Val h. Smith1* and robertc. Mcbride. 2015. Key ecological challenges in sustainable algal biofuels production. J. Plankton Res. 37(4): 671-682.

Voort, M.P.J. van der, Vulsteke, E., Visser, C.L.M. de. 2015. Marco-economics of Algae products, Public Output report WP2A7.02 of the EnAlgae project. 47 pp. http://www.enalgae.eu/public-deliverables.htm 